\title{
CAPITÃES DA AREIA: ALGUNS ENSAIOS
}

\section{Clóvis Demarchi* \\ Lucilaine Ignacio da Silva*}

\section{Resumo}

Capitães da Areia, obra literária de Jorge Amado é a inspiração para a análise de questões jurídicas e sociais relacionadas ao tema criança e o adolescente. Faz-se também abordagem rápida acerca das conquistas relacionadas a Doutrina da Proteção Integral. A obra enfatiza a história de sobrevivência de crianças marginalizadas que não difere do que se encontra na realidade contemporânea. $\mathrm{O}$ estudo utiliza-se do método indutivo combinado com a narrativa e, a técnica de pesquisa bibliográfica, cuja análise e interpretação dos resultados, terão caráter qualitativo, na tentativa de oferecer uma apreciação global sobre o tema abordado.

Palavras-chave: Capitães da Areia, Criança e Adolescente, Literatura, Proteção Integral, Marginalização.

\section{CAPTAINS OF THE SAND: SOME ESSAYS}

\begin{abstract}
:
Captains of the Sand, literary work of Jorge Amado is the inspiration for the analysis of legal and social issues related to the topic of child and adolescent. Makes a quick approach on the achievements related to the Doctrine of Integral Protection. Emphasizes the survival story of marginalized children that does not differ from what is found in contemporary reality. The study uses the inductive method combined with the narrative and, the technique of bibliographic research, whose analysis and interpretation of the results will have a qualitative character in an attempt to offer a global appreciation on the subject addressed.
\end{abstract}

\footnotetext{
* Doutor e Mestre em Ciência Jurídica pela Universidade do Vale do Itajaí. Professor na graduação em Direito e no Curso de Doutorado e Mestrado em Ciência Jurídica da UNIVALI. Líder do grupo de pesquisa em Direito Educacional e Normas Técnicas e membro do grupo de pesquisa em Direito, Constituição e Jurisdição. Endereço eletrônico: demarchi@univali.br.

* Doutoranda em Direito, pelo Programa de Pós-Graduação em Direito da Universidade Federal de Santa Catarina (UFSC). Mestre em Ciência Jurídica pela Universidade do Vale do Itajaí (UNIVALI). Pesquisadora do Núcleo de Pesquisa Direito e Fraternidade (UFSC). Pesquisadora do Núcleo de Estudos Jurídicos e Sociais da Criança e do Adolescente - Nejusca - da Universidade Federal de Santa Catarina (UFSC).
} 
Keywords: Captains of the Sands, Child and Adolescent, Literature, Integral Protection, Marginalization.

\section{INTRODUÇÃO}

O romance Capitães da Areia $^{1}$ de Jorge Amado $^{2}$ pertence à segunda fase do Modernismo no Brasil (1930-1945), cuja narrativa apresenta claramente as transformações políticas, econômicas e sociais da época.

De maneira panfletária, o autor denuncia o problema de menores abandonados e de menores infratores na Cidade de Salvador, Bahia com demonstrações cotidianas de violência, abusos, criminalidade, preconceitos e prostituição. Entretanto, em meio à denúncia percebemse as aspirações, sonhos e ideais ingênuos peculiares a qualquer criança.

Considerando que a história se desenvolve em meados de 1937, sob o contexto histórico da ditadura no Brasil, a problemática abordada ainda se faz atual e presente. É possível analisar no romance em questão, os delitos cometidos pelos meninos, apesar da abordagem romântica que os minimiza, assim como a posição do Estado e da Sociedade frente aos acontecimentos que ora faz dessas crianças infratores, ora as torna vítimas.

Jorge Amado criou personagens envolventes, de tal maneira que não há um personagem principal, um protagonista, e sim vários protagonistas, as crianças; assim como é na Sociedade. De modo lúdico, o autor revela várias mensagens que, dentre as quais, uma se destaca independente do contexto histórico, geográfico e social, a de que criança é e sempre será criança, na sua forma mais singela e pura.

Assim, diante da narrativa romântica de Capitães da Areia e sob a égide do Princípio da Proteção Integral ${ }^{3}$, discorrer-se-á de alguns destaques do cotidiano das crianças do trapiche

\footnotetext{
${ }^{1}$ Foi publicado em 1937 e teve sua primeira edição apreendida e exemplares queimados em praça pública de Salvador por autoridades da ditadura. A partir de 1944, quando uma nova edição é lançada, o romance entra para a história da literatura brasileira, assim como outros livros do autor, traduzidos para outros idiomas e adaptados para rádio, teatro e cinema.

2 Jorge Amado nasceu em Itabuna (BA), em 10 de agosto de 1912, e passou a infância em Ilhéus e desenvolveu uma literatura politicamente engajada. Nos anos seguintes, publicou "Cacau” (1933), "Suor" (1934), "Jubiabá" (1935) e "Capitães da Areia" (1937). Faleceu em 6 de agosto de 2001, em Salvador. É o romancista brasileiro mais traduzido e conhecido em todo o mundo.

${ }^{3}$ Para Josiane Rose Petry Veronese, “a Convenção sobre os Direitos da Criança orientou-se no sentido de alcançar o interesse superior de cada criança em todas as ações, englobando uma grande gama de direitos humanos, civis, políticos, sociais e culturais, reconhecidos a todas as pessoas, evidenciando a impossibilidade de garantia de um direito específico, sem que se passe a garantir todos os demais direitos correlatos. Essa evolução histórica dos instrumentos internacionais de proteção à criança, fundada inicialmente em normas isoladas, para um sistema de caráter universal, orientado pelo seu reconhecimento como titular de direitos especiais, constituiu, assim o novo CONPEDI LAW REVIEW | Braga - Portugal | v. 3 | n. 2 | p. 42 - 56 | JUL/DEZ. 2017
} 
com o intuito de identificar cenários de fragilidades no tocante à proteção da criança e assim, aspirar o futuro que as aguarda.

\section{A INFÂNCIA NAS CARTAS EM CAPITÃES DA AREIA}

A infância narrada em Capitães da Areia se delineia a partir de uma sequência de cartas encaminhadas à redação de um jornal (Jornal da Tarde), que denunciam o comportamento das crianças que aterrorizam a Cidade de Salvador. A notícia veiculada no jornal sob o título "Crianças Ladronas" dá ensejo a uma série de cartas encaminhadas ao jornal relatando as atividades criminosas que envolvem o grupo de meninos.

A notícia primeira, veiculada, relata especificamente o assalto à casa do Comendador e apresenta o grupo de meninos do trapiche como o responsável pelas violências ocorridas nas redondezas e concomitantemente lhes atribui características pontuais, bem como algumas fragilidades experienciadas pelas crianças.

Essas crianças que tão cedo se dedicaram à tenebrosa carreira do crime não tem moradia certa ou pelo menos a sua moradia ainda não foi localizada. Como também ainda não foi localizado o local onde escondem o produto dos seus assaltos, que se tornam diários, fazendo jus a uma imediata providência do juiz de menores e do dr. Chefe de polícia. [...] Esse bando que vive da rapina se compõe, pelo que se sabe, de um número superior a cem crianças das mais diversas idades, indo desde os oito aos dezesseis anos. Crianças que, naturalmente devido ao desprezo dado à sua educação por pais pouco servidos de sentimentos cristãos, se entregaram no verdor dos anos a uma vida criminosa. [...] (AMADO, 2009, p. 9)

Da narrativa acima se destacam questões pontuais da infância das crianças do trapiche que, não obstante também se faz presente nos dias atuais, como a falta de moradia, o preconceito, a discriminação, o delito, a violência, ou seja, atos reconhecidamente atentatórios à dignidade humana.

Rossi (2009, p. 27) assinala:

"[...] as crianças abandonadas de Capitães da Areia encontravam na "aventura da liberdade nas ruas" e na união do grupo meios de restituir os bens e os afetos que a orfandade lhes negara. Uma orfandade não apenas familiar, mas de todo o aparato político-institucional que os tratavam como os "delinquentes que infestam nossa urbe"”.

paradigma de proteção infantoadolescente identificado como "Doutrina da Proteção Integral". (SANCHES; VERONESE. 2016. p. 100-101) 
Em uma das cartas publicadas, urge a providência da polícia e do juizado de menores para a extinção do bando e seu recolhimento aos institutos de reforma de crianças, uma vez que a cidade precisaria dormir em paz com o sono merecido.

Na mesma, tem-se o relato do pequeno Raul, um garoto de onze anos, aluno aplicado de um colégio de renome da Cidade de Salvador, que expõe sua conversa com o terrível chefe dos Capitães da Areia na ocasião do assalto:

- Ele disse que eu era um tolo e não sabia o que era brincar. Eu respondi que tinha uma bicicleta e muito brinquedo. Ele riu e disse que tinha a rua e o cais. Fiquei gostando dele, parece um desses meninos de cinema que fogem de casa para passar aventuras. (AMADO, 2009, p. 12)

Duas realidades distintas, duas concepções de infância também distintas, ou seja, de acordo com a realidade de cada uma das crianças. Entretanto, o ponto em comum é a vivência, a experiência que se esgota em cada uma delas.

Em outras duas cartas, a do Secretário do Chefe de Polícia e a do Juiz de Menores à redação do jornal o enredo se dá em torno das providências não tomadas pela polícia em relação aos menores por ineficiência do juiz, que se justifica dizendo que "[...] ao juizado de menores não compete perseguir e prender os menores delinquentes e, sim, designar o local onde devem cumprir pena, nomear curador para acompanhar qualquer processo contra eles instaurado, etc." (AMADO, 2009, p. 14).

Há também, o questionamento do juiz de menores ao chefe de polícia, do "por que" destes meninos fugirem do reformatório e se tornarem ainda mais perversos, como se o exemplo recebido fosse mau e daninho.

Constata-se das referidas cartas, a relação entre crime e castigo, direitos e deveres, bem como a quem compete a atribuição de regular tais ocorrências.

Em uma terceira carta, fica evidenciada a preocupação de uma mãe com os relatos publicados no jornal, em especial com o reformatório, que é o local segundo ela, para onde mandam os filhos dos pobres. Lugar de guardas sem alma, o inferno em vida onde seu filho passou seis meses e que talvez não vivesse por mais seis, devido às surras de duas a três vezes ao dia que eram dadas como bom exemplo e correção. Como se não bastasse, esta sugere ao jornal, conversar com o padre José Pedro, conhecido dos meninos e que poderia confirmar sua história. Por carta, o padre José Pedro esclarece:

[...] sou obrigado a sair da obscuridade em que vivo para vir vos dizer que infelizmente Maria Ricardina tem razão. As crianças no aludido reformatório são tratadas como feras, essa é a verdade. Esqueceram a lição do suave mestre, sr. redator, e em vez de conquistarem as crianças com bons tratos, fazem-nas 
mais revoltadas ainda com espancamentos seguidos e castigos físicos verdadeiramente desumanos. Eu tenho ido lá levar às crianças o consolo da religião e as encontro pouco dispostas a aceitá-lo devido naturalmente ao ódio que estão acumulando naqueles jovens corações tão dignos de piedade. $\mathrm{O}$ que tenho visto, sr. redator, daria um volume. (AMADO, 2009, p. 18).

Por último, o Diretor do Reformatório se manifesta ao Jornal da Tarde, se referindo às cartas publicadas e, em sua defesa, denuncia a negligência e o descaso das mães que preferem ver seus filhos nas ruas, ao invés do reformatório, pois nas ruas eles dão mais lucro com o produto de seus furtos.

De todo modo, o que se percebe dos relatos das cartas encaminhadas ao Jornal da Tarde, são fatos de uma história "fictícia" e "real". São questões sociais que acontecem diariamente, seja na "cidade da Bahia”, seja nas demais cidades do Brasil e do mundo.

As crianças são atiradas à marginalidade, apresentadas às mais diversas formas de sujeição: à fome, à miséria, à violência, ao abandono, ao preconceito, à discriminação, à humilhação, às ausências, enfim, são relatos atuais que aqui destacados serão tratados no capítulo seguinte.

\section{COADJUVANTES E PROTAGONISTAS DE UM CENÁRIO SOCIAL}

No capítulo anterior, destacaram-se alguns cenários de Capitães da Areia que fosse possível identificar fragilidades às quais as crianças estão sujeitas, tanto na abordagem fictícia como na vida real.

Cumpre-nos primeiramente destacar que, a criança e o adolescente no incurso da história ganhou destaque no sentido de serem compreendidos como sujeitos e autores de sua própria história. Superou-se a ótica de que eram objetos de uma ideologia tutelar.

Os relatos demonstrados nos cenários de Capitães da Areia, ainda persistem, mas, deve-se admitir que houve e ainda haverá, mudanças de paradigmas nesta seara, como desde uma "Doutrina da Situação Irregular" que caracteriza um Direito Tutelar até uma "Doutrina da Proteção Integral" que caracteriza um Direito Protetor-responsabilizador. (WOLKMER; LEITE, 2016, p. 52).

A história da legislação brasileira em torno do tema da criança e do adolescente remonta desde 1823 com as legislações e iniciativas assistenciais, dando ensejo às primeiras leis e instituições que se firmaram gradativamente. 
No período colonial e do Império, Wolkmer e Leite (2016, p. 53) observam que os serviços de assistência a menores se dava em três níveis, sendo, uma de forma criativa, prestada por igrejas e associações civis; outra filantrópica (firmada na aristocracia rural e mercantilista) e uma terceira, menor, oriunda de algumas realizações da Coroa portuguesa.

Foi, entretanto, a partir de 1920 que a opinião de que ao Estado caberia assistir a criança, se fortaleceu.

O Código de Menores de 1927, considerado o primeiro Código da América Latina, uma vez que conseguiu corporificar leis e decretos que, desde 1902, propunham-se a aprovar um mecanismo legal que desse especial relevo à questão do menor de idade, alterou e substituiu concepções obsoletas como as de discernimento, culpabilidade, responsabilidade, disciplinando, ainda, que a assistência à infância deveria passar da esfera punitiva para a educacional, algo extremamente inovador à época, fruto da influência do positivismo, que defendia que quanto mais cedo houvesse uma intervenção, no sentido de tratamento, sobre este menor de idade - delinquente ou abandonado -, maiores seriam as chances de uma recuperação e reintegração social. (WOLKMER; LEITE, 2016, p. 54).

Muitas questões controversas são postas em relevo com o Código de Menores de 1927. Questões tais, que são pontuadas no romance de Jorge Amado de maneira lúdica, porém lúcida, da vida das crianças que se encontram nos semáforos, nos viadutos e ruas das cidades brasileiras.

O artigo 227 da Constituição do Brasil de 1988 incorporou a teoria da Proteção Integral $^{4}$ das Nações Unidas e com ela passa a reconhecer crianças e adolescentes como sujeitos de direitos fundamentais. Com tal incorporação, as responsabilidades passam a ser compartilhadas entre a família, o Estado e a Sociedade civil, de maneira que se concretizem os direitos declarados:

Art. 227. É dever da família, da sociedade e do Estado assegurar à criança e ao adolescente, com absoluta prioridade, o direito à vida, à saúde, à alimentação, à educação, ao lazer, à profissionalização, à cultura, à dignidade, ao respeito, à liberdade e à convivência familiar e comunitária, além de coloca-los a salvo de toda forma de negligência, discriminação, exploração, violência, crueldade e opressão. (BRASIL, 1988).

Veronese (2017, p. 3) ensina que "quando a legislação pátria recepcionou a Doutrina da Proteção Integral fez uma opção que implicaria num projeto político-social para o país, [...]”. Segundo a autora, a doutrina da Proteção Integral apresenta por fundamento dois pilares de

${ }^{4}$ A proteção integral reconhecida na Constituição Federal de 1988 consolida-se basicamente no art. 227, que declara direitos especiais da criança, do adolescente e do jovem (acrescentado ao texto original do art. 227, por força da E.C n. 65 de 2010), e devem ser garantidos pela família, pelo Estado e pela Sociedade. Salienta-se que, esta concepção foi recepcionada de forma plena pelo Estatuto da Criança e do Adolescente. (VERONESE, 2017, p. 2). 
suma importância, a dizer, a concepção da criança e do adolescente como "sujeitos de direitos" e esta, em conjunto com a família, a sociedade e o Estado.

\begin{abstract}
A Doutrina da Proteção Integral implica, sobretudo:
1 - A infância e a adolescência admitidos como prioridade imediata $e$ absoluta, exigindo uma consideração especial, o que significa que a sua proteção deve sobrepor-se a quaisquer outras medidas, tudo isso objetiva o resguardado de seus direitos fundamentais;

2 - O princípio do melhor interesse da criança, este princípio não deve ser visto de uma forma fantasiosa ou sonhadora, mas como algo concreto, considerando que cabe à família, portanto aos pais ou responsáveis garantirlhe proteção e cuidados especiais; ressalta-se o papel importante da comunidade, na sua efetiva intervenção/responsabilização com os infantes e adolescentes, daí decorre a criação dos Conselhos Tutelares e, ainda, a atuação do Poder Público com a criação de meios/instrumentos que assegurem os direitos proclamados;

3 - Reconhece a família como o grupo social primário e ambiente "natural" para o crescimento e bem-estar de seus membros, especificamente das crianças, ressaltando o direito de receber a proteção e a assistência necessárias, a fim de poder assumir plenamente suas responsabilidades dentro da comunidade na idade apropriada. (VERONESE, 2017, p. 4).
\end{abstract}

Destarte, este entendimento conforme acentuado por Veronese (2017, p. 4), resultou na "prioridade absoluta constitucional", determinada pelo artigo 227 da CF/88 e regulamentada na Lei $n^{\circ} 8.069 / 1990$ (Estatuto da Criança e do Adolescente), em específico no seu art. $4^{\circ}$, parágrafo único ${ }^{5}$.

Por absoluta prioridade é importante ressaltar o que leciona Liberatii (1991, p. 4-5):

[...] devemos entender que a criança e o adolescente deverão estar em primeiro lugar na escala de preocupação dos governantes; devemos entender que, primeiro, devem ser atendidas todas as necessidades das crianças e adolescentes. Por absoluta prioridade, entende-se que na área administrativa, enquanto não existem creches, escolas, postos de saúde, atendimento preventivo e emergencial às gestantes, dignas moradias e trabalho, não se deveria asfaltar ruas, construir praças, sambódromos, monumentos artísticos etc., porque a vida, a saúde, o lar, a prevenção de doenças são mais importantes que as obras de concreto que ficam para demonstrar o poder do governante.

5 Art. $4^{\text {o }}$ É dever da família, da comunidade, da sociedade em geral e do poder público assegurar, com absoluta prioridade, a efetivação dos direitos referentes à vida, à saúde, à alimentação, à educação, ao esporte, ao lazer, à profissionalização, à cultura, à dignidade, ao respeito, à liberdade e à convivência familiar e comunitária.

Parágrafo único. A garantia de prioridade compreende:

a) primazia de receber proteção e socorro em quaisquer circunstâncias;

b) precedência de atendimento nos serviços públicos ou de relevância pública;

c) preferência na formulação e na execução das políticas sociais públicas;

d) destinação privilegiada de recursos públicos nas áreas relacionadas com a proteção à infância e à juventude. 
À criança e o adolescente, muito se acrescentou ante a elaboração, incorporação e aprovação de legislações e dispositivos importantes para sua regulação, proteção e integridade. Houve alteração significativa no que diz respeito à intervenção arbitrária do Estado na vida das crianças, adolescentes e jovens que, antes se prestavam ao modelo de Atendimento de Situação Irregular6.

Contudo, diante do contexto regulamentar da doutrina da Proteção Integral consagrado pela Constituição Federal de 1988, importa ressaltar que o Estatuto da Criança e do Adolescente assume o papel de instrumentalizar a aplicação de tais direitos. Cabe ao Estatuto estabelecer responsabilidade e procedimentos com vistas à realização de suas prescrições e, acima de tudo, concretizar os direitos atribuídos aos seus respectivos destinatários.

\section{A JUVENTUDE DOS 'CAPITÃES DA AREIA'}

Os novos paradigmas de proteção à criança e o adolescente, conferem a estes, condição especial e essencial para o usufruto da vida. À luz da história, e do tempo, revela-se especial universalidade em direitos humanos.

Os cenários destacados do romance, Capitães da Areia trazem subsídios para uma análise, no mínimo, temporal, geográfica, social, histórica e jurídica acerca da temática criança e adolescente.

A experiência da ineficácia do Código de Menores e a efetivação da força cogente internacional na Doutrina da Proteção Integral serviram para declarar e estabelecer no Brasil um certo núcleo fundamental de proteção da criança e do adolescente face à exploração prejudicial para qualquer aspecto de seu bem-estar. (MESSA; CALHAO, 2015, p. 331)

Um estudo reflexivo a partir do romance possibilita a análise de fatores comuns como a comunidade, as contingências psicológicas e/ou sociais, a formação cultural, intelectual, econômica que, todo indivíduo enfrenta no cotidiano desde a mais tenra idade.

Assim, cabe a reflexão da(s) realidade(s) experienciadas(s) durante a infância e possíveis consequências esperadas na juventude. A realidade de um menor infrator, por exemplo, deve ser dimensionada de modo, a saber, se este menor foi criado junto à sua família,

\footnotetext{
6 “As leis e práticas que existiam antes de aprovada a Convenção sobre os Direitos da Criança em relação à infância respondiam a um modelo que hoje conhecemos como "modelo tutelar", "filantrópico", da "situação irregular" ou "assistencialista", cujo ponto de partida era a consideração da criança como objeto de proteção e não como sujeito de direitos, [...].” (SANCHES; VERONESE, 2016, p. 110).
} 
se esta família se fez presente e em que condições, se lhe foi proporcionado o convívio social e a apreciação aos valores morais, etc.

Norberto Bobbio leciona:

O problema grave de nosso tempo, com relação aos direitos do homem, não era mais o de fundamentá-los, e sim o de protegê-los. [...] O problema que temos diante de nós não é filosófico, mas jurídico e, num sentido mais amplo, político. Não se trata de saber quais e quantos são esses direitos, qual é sua natureza e seu fundamento, se são direitos naturais ou históricos, absolutos ou relativos, mas sim qual é o modo mais seguro para garanti-los, para impedir que, apesar das solenes declarações, eles sejam continuamente violados. (BOBBIO, 1992, p. 25)

Das cartas do romance, Capitães da Areia, percebe-se a negligência destes aspectos. A obra literária é sem dúvida um documentário social e, a narrativa do autor e sua linguagem coloquial apresentam os atos ilícitos cometidos pelo grupo de meninos que viviam no trapiche de forma minimizada, de maneira a tornar as crianças cativantes, pois a condição de penúria, de descaso, fala mais alto.

O conflito que move o romance é o mesmo que move a sociedade. São velhos contrapesos conhecidos, como pobres e ricos, pequenos marginais contra uma sociedade opressora e vice-versa. Nesse contexto, não há dúvidas de que a juventude é uma construção social e que assume concepções e compreensões históricas variadas e, ao refletir sobre a juventude faz-se necessário pensar em diversos processos de diferenciação cuja maior ênfase observa-se na infância e na adolescência.

\begin{abstract}
A realidade social demonstra, no entanto, que não existe somente um tipo de juventude, mas grupos juvenis que constituem um conjunto heterogêneo, com diferentes parcelas de oportunidades, dificuldades, facilidades e poder nas sociedades. Nesse sentido, a juventude, por definição, é uma construção social, ou seja, a produção de uma determinada sociedade originada a partir das múltiplas formas como ela vê os jovens, produção na qual se conjugam, entre outros fatores, estereótipos, momentos históricos, múltiplas referências, além de diferentes e diversificadas situações de classe, gênero, etnia, grupo etc. (ESTEVES; ABRAMOVAY, 2007, p. 23).
\end{abstract}

De fato, a juventude é uma construção social, e a obra, 'Os Capitães da Areia' de Jorge Amado, revela-nos variadas trajetórias e desfechos de alguns meninos quando jovens, quase adultos que devem ser consideradas. É uma etapa da vida que possui características próprias, mas, constitui uma ponte entre a criança e o adulto. Neste sentido, Zaneti (2001, p. 52) lembra que, nessa "etapa da vida há uma potencialidade latente "disponível” que pode ser mobilizada em diferentes direções, por diferentes motivações". 
Jorge Amado explora o sonho e a utopia daquelas crianças nas mais diversas possibilidades. Lirismo e dramas permeiam a vida narrada daquelas crianças e, algumas delas na vida quase adulta se revelam extraordinariamente diferentes, a considerar sua infância.

[...] O mais impressionante na vida dessas crianças "sem pai, sem mãe, sem mestre" é a sede de amor e ternura, o desejo recorrente e desesperado de pertencer a uma família e conquistar um lugar digno na sociedade. (AMADO, 2009, p.267).

É um enfrentamento social constante pelo qual passam as crianças do trapiche e, na sua fase de juventude, não é diferente. A todo tempo, o texto revela emoções de terror, piedade e admiração.

Apesar da infância conturbada dos meninos do trapiche, alguns deles se tornaram jovens realizados que conseguiram sobreviver às penúrias sociais e culturais, impostas pela sociedade e o Poder Público.

O que teria ocorrido com estes jovens, na ocasião de sua infância, que poderia tê-los poupado de uma vida marginalizada na fase quase adulta?

Esse é um questionamento que remete a uma passagem particular da obra e que também permite refletir a realidade sobre o tripé do sistema, qual seja: o social - o político - e o jurídico.

Dentre vários capítulos que compõem o romance, alguns são particularmente significativos. O capítulo “As Luzes do Carrossel”, mostra o bando de meninos a brincar num ultrapassado carrossel, esquecendo por alguns instantes a vida de delinquência e violência que praticavam.

No começo da noite caiu uma carga-d'água. Também as nuvens pretas logo depois desapareceram do céu e as estrelas brilharam, brilhou também a lua cheia. Pela madrugada os Capitães da Areia vieram. O Sem-Pernas botou o motor para trabalhar. E eles esqueceram que não eram iguais às demais crianças, esqueceram que não tinham lar, nem pai, nem mãe, que viviam de furto como homens, que eram temidos na cidade como ladrões. Esqueceram as palavras da velha de lorgnon. Esqueceram tudo e foram iguais a todas as crianças, cavalgando os ginetes do carrossel, girando com as luzes. As estrelas brilhavam, brilhava a lua cheia. Mas, mais que tudo, brilhavam na noite da Bahia as luzes azuis, verdes, amarelas, roxas, vermelhas do Grande Carrossel Japonês. (AMADO, 2009, p. 79-80)

Essa passagem é o contraponto à opinião vigente na alta sociedade baiana em relação aos Capitães da Areia. A imagem de que os meninos do trapiche eram bandidos sem recuperação e que poderiam e/ou deveriam ser tratados de forma desumana no reformatório, é 
confrontada com a situação harmoniosa, que revela a essência de crianças socialmente desamparadas.

Jorge Amado consegue criar um universo de fantasia, entrelaçando fantasia, subjetivismo, comoção, linguagem figurada, aflorando a verdadeira face de uma criança:

[...] as luzes do carrossel girando loucamente movimentadas pelo Sem-Pernas. Era como num sonho, sonho muito diverso dos que o Sem-Pernas costumava ter nas suas noites angustiosas. E pela primeira vez seus olhos sentiram-se úmidos de lágrimas que não eram causadas pela dor ou pela raiva. E seus olhos úmidos miravam Nhozinho França como a um ídolo. Por ele até a garganta de um homem o Sem-Pernas abriria com a navalha que traz entre a calça e o velho colete preto que lhe serve de paletó. (AMADO, 2009, p. 61 e 62).

As necessidades e os conflitos experienciados durante a vida no trapiche, certamente não destruiu os ideais e sonhos que nutriam enquanto crianças. Não diferente é o que se passa fora da ficção, onde milhares de pessoas (crianças, jovens e adultos) são desprovidas de acesso aos insumos básicos para uma vida digna.

A juventude reservada aos meninos do trapiche, assim como à juventude contemporânea, é uma loteria. A familiaridade entre a ficção literária e a realidade é a revelação de uma exclusão social perene e silenciosa que avança continuamente e atinge aquele que cruzar seu caminho.

\section{CONCLUSÃO}

A reflexão apresentada a partir do romance de Jorge Amado, Os Capitães da Areia com a Doutrina da Proteção Integral é uma aproximação do direito e da literatura que possibilita uma análise jurídica pela moldura da sociedade.

A literatura permite trabalhar o direito na essência das relações humanas por um objeto específico, ou seja, a linguagem.

"Direito e Literatura" propõe uma inversão da lógica e da justificativa existencial do direito. Ao seu estudioso, é requisitado o abandono temporário de sua formação positivista e analítica do direito para permitir-se compreendêlo sob um enfoque linguístico e cultural. Aqui, abandonam-se provisoriamente os estudos científicos e institucionais do direito a ponto de repensar sua categorização como ciência e aceita-lo como uma narrativa social constantemente constituída e desenvolvida. (OLIVO; SIQUEIRA, 2016, p.321-322). 
Capitães da Areia retrata a vida de meninos de rua dos anos 30 a 50 que, à época de sua publicação repercutiu de forma polêmica a ponto de ser censurada pelo Estado Novo e queimada em praça pública. Fato que não causa espanto, pois, a obra literária de Jorge Amado, subverteu o senso comum e fez de meninos de rua, acusados pela sociedade de pervertidos e marginais à condição de heróis e vítimas.

Com a aproximação dos estudos do direito e da literatura a academia ganhou novo espaço institucional, a registrar em meados da década de 1960, como se apresenta dos estudos de Olivo e Siqueira (2016, p. 323), "Ela surgiu como uma das várias tendências antipositivistas do mais amplo movimento "Direito e sociedade", atuando na formação do profissional do direito de forma a resgatar aspectos humanísticos de que as carreiras jurídicas se afastam”.

A peculiaridade da obra em análise é justamente a possibilidade de conferir ao leitor um meio de enxergar as práticas ilegais dos meninos do trapiche sob os desdobramentos de uma estrutura social que por vezes, se revela perversa e que, com o auxílio prestado pela junção do Direito e da Literatura, evidencia-se outro âmbito de compreensão do direito.

O entendimento de uma natureza comum entre o direito e a literatura, pautado na linguagem como meio de manifestações sociais, pretende superar o dualismo intuitivo entre o princípio estético da literatura e da justiça, princípio prático da atividade jurídica. [...] Essa superação inicial do dualismo entre o direito e a literatura possibilitará a investigação de diversas perspectivas de estudo dentro do movimento "Direito e Literatura", entre elas o reconhecimento de um novo campo de retórica fundamental para uma compreensão dinâmica do direito. (OLIVO; SIQUEIRA, 2016, p. 323).

O estudo da Criança e do Adolescente por meio da Literatura evidencia de forma clara os impasses e insuficiências que necessitam de maior atenção ou de contínua atenção. Tornase evidente que as conquistas legislativas e a inclusão de práticas emergentes vinculando o Estado e a Sociedade é o caminho a percorrer para minimizar as mazelas da coletividade humana.

No Ensaio sobre a cegueira, de José Saramago (1995, p. 308-310), o autor ressalta que vive-se tempos de cegueira e não de cegos, que as pessoas veem e, mesmo vendo, não veem. É a prática usual às necessidades latentes da sociedade para a sociedade, do Poder Público para esta.

No que tange aos direitos das crianças e dos adolescentes, a Doutrina da Proteção Integral é compreendida por Souza (2001, p. 60), como “o embrião de uma nova doutrina relativa aos cuidados com a criança, de uma nova maneira de enxergar o indivíduo detentor de direitos e prerrogativas". 
A Doutrina da Proteção Integral é um novo marco no qual a criança passa a ser compreendida como sujeito-cidadão, ou por assim dizer, um sujeito de direitos e não mais um receptor das ações do Estado ou daqueles a quem se atribui tal responsabilidade. As questões teóricas que envolvem a proteção criança é a mesma que envolve a proteção universal do sujeito de direito.

Segundo Smanio e Bertolin (2015, p. 63), “[...] a efetivação desta proteção integral encontra grandes fragilidades em nossa realidade social, demandando uma Política Pública de Estado voltada à consecução dos Direitos Humanos da Criança e do Adolescente".

No entanto, cabe admitir que o Direito da Criança e do Adolescente possui na sua evolução histórica, instrumentos relevantes, a destacar a Doutrina da Proteção Integral, que reconhece e confere proteção à criança, anteriormente isolada do sistema, sob um caráter universal, como titular de direitos especiais.

Estudar sob o viés da literatura aspectos destacados dos direitos atribuídos à criança e o adolescente, sobretudo na obra de Jorge Amado que se utiliza de recursos retóricos e poéticos agregados ao tema da crítica à exclusão social, evoca questões como orfandade, preconceito, discriminação e abandono social, bem a perda precoce da inocência infantil envolta a uma carência afetiva que estimula a revolta e a violência.

Mesmo em meio a tantas emoções que geram sofrimento, os meninos de Capitães da Areia não perde o desejo de serem amparadas, de ter vida melhor, carinho e amor.

Os sonhos são a mola propulsora dessas crianças. Tanto as crianças dos Capitães da Areia, como as da sociedade em geral, na reivindicação de seus direitos que continuam impulsionando a luta por uma realidade mais justa e igualitária.

A literatura de Jorge Amado representa sobremaneira, as incertezas do indivíduo marginalizado diante de um contexto social opressor. A linguagem poética conferida pelo autor, possibilita a criação de modos imaginários para suportar a vida sofrida e enfrentada pelas crianças, que a princípio parece não haver esperança para impulsionar e criar perspectivas futuras. Contudo, é possível perceber ao longo da narrativa, que os personagens demonstram sentimentos como coragem e perseverança diante dos problemas apresentados.

\section{BIBLIOGRAFIA}

ANDREUCCI, A. C. P. T.; CARACIOLA, A. B.; JUNQUEIRA, M. A. (Orgs.). Estatuto da Criança e do Adolescente: 25anos. São Paulo: LTr, 2015. 
AMADO, Jorge. Capitães da Areia. Posfácio de Milton Hatoum. São Paulo: Companhia das Letras, 2009. $280 \mathrm{p}$.

BRASIL. Constituição Federal da República Federativa do Brasil. 1988.

BRASIL. Lei no 8.069 de 13 de julho de 1990. Dispõe sobre o Estatuto da Criança e do Adolescente e dá outras providências. Brasília, DF, 13 jul. 1990. Disponível em: < http://www.planalto.gov.br/ccivil_03/leis/L8069.htm>. Acesso em: 04 jun. 2017.

COSTA, M. M. M. da.; PORTO, R. T. C.; REIS, S. S. (Orgs.). Direito, Cidadania e Políticas Públicas IV. Curitiba: Multidéia, 2010. 320 p.

ESTEVES, L. C. G.; ABRAMOVAY, M. Juventude, Juventudes: pelos outros e por elas mesmas. ABRAMOVAY, M.; ANDRADE, E. R.; ESTEVES, L. C. G. (Orgs.) Juventudes: outros olhares sobre a diversidade. Brasília: Ministério da Educação, Secretaria da Educação Continuada, Alfabetização e Diversidade; UNESCO, 2007. p. 21-56.

LIBERATTI, Wilson Donizetti. O Estatuto da Criança e do Adolescente - Comentários. São Paulo: IBPS, 1991.

MESSA, A. F.; CALHAO, A. E. P. Proteção da Criança e do Adolescente contra Abuso e Negligência. In. ANDREUCCI, A. C. P. T.; CARACIOLA, A. B.; JUNQUEIRA, M. A. (Orgs.). Estatuto da Criança e do Adolescente: 25anos. São Paulo: LTr, 2015. p. 328-334.

OLIVO, L. C. C.; SIQUEIRA, A. B. P. de. Direito e Literatura: Perspectivas para um "Novo" Direito. WOLKMER, A. C., LEITE, J. R. M. (Orgs.) Os "novos" direitos no Brasil: natureza e perspectivas - uma visão básica das novas conflituosidades jurídicas. 3. ed. São Paulo: Saraiva, 2016.

ROSSI, Luiz Gustavo Freitas. A militância política na obra de Jorge Amado. In: GOLDSTEIN, Norma. SCHWARCZ, Lilia Moritz (orgs.). O universo de Jorge Amado: orientações para o trabalho em sala de aula. São Paulo: Companhia das Letras, 2009. (Caderno de Leituras).

SANCHES, Helen Crystine Corrêa.; VERONESE, Josiane Rose Petry. Justiça da Criança e do Adolescente: Da vara de menores à vara da infância e juventude. 1. ed. Rio de Janeiro: Lumem Juris, 2016. 328 p.

SARAMAGO, José. Ensaio sobre a cegueira. São Paulo: Companhia das Letras, 1995.

SMANiO, G. P.; BERTOLIN, P. T. M. A Doutrina da Proteção Integral e seus ainda restritos efeitos sobre as Políticas Públicas voltadas à Criança e ao Adolescente. ANDREUCCI, A. C. P. T.; CARACIOLA, A. B.; JUNQUEIRA, M. A. (Orgs.). Estatuto da Criança e do Adolescente: 25anos. São Paulo: LTr, 2015.

SOUZA, Sérgio Augusto Guedes Pereira de. Os direitos da criança e os direitos humanos. Porto Alegre: Sérgio Antonio Fabris Editor, 2001.

VERONESE, J. R. P. (Aut./Org.). [et. al.]. Direito da Criança e do Adolescente: Novo curso - novos temas. 1. ed. Rio de Janeiro: Lumen Juris, 2017. 828 p. 
WOLKMER, A. C., LEITE, J. R. M. (Orgs.) Os "novos" direitos no Brasil: natureza e perspectivas - uma visão básica das novas conflituosidades jurídicas. 3. ed. São Paulo: Saraiva, 2016.

ZANETI, Hermes. Juventude e revolução: uma investigação sobre a atitude revolucionária juvenil no Brasil. Brasília: Editora Universidade de Brasília, 2001. 242 p. 